\title{
Penanggulangan Anemia melalui Kader Kokoa Moringa Oleifera (Komo)
}

\author{
Azizatul Hamidiyah ${ }^{*}$, Raudatul Hikmah ${ }^{2}$ \\ ${ }^{1,2}$ Prodi D3 Kebidanan Fakultas Ilmu Kesehatan, Universitas Ibrahimy Sukorejo Situbondo \\ *azizatulhamidiyah@ibrahimy.ac.id
}

Received 23 August 2018; Accepted 23 August 2018; Published 27 September 2018

\begin{abstract}
ABSTRAK
Camilan siap saji yang terstandarisasi untuk dikonsumsi ibu hamil sebagai pengganti tablet $\mathrm{Fe}$ sementara ketika rasa mual akibat sensitivitas pada ibu hamil sangat dibutuhkan mengingat tingginya kejadian anemia ibu hamil. Salah satunya camilan sehat tersebut adalah coklat (Kokoa) kelor (Moringa Oleifera). Sehingga dalam upaya penurunan kejadian anemia ibu hamil, perlu dilakukan pendampingan Kader Kokoa Moringa Oleifera (KOMO) dalam pembuatan camilan sehat coklat kelor. Tujuan kegiatan pendampingan kader Kokoa Moringa Oleifera (KOMO) ini adalah untuk meningkatkan keterampilan kader tentang camilan sehat KOMO dalam menanggulangi ibu hamil anemia. Kegiatan pendampingan dilakukan di 2 posyandu Desa Sumberejo dan Mimbo Sumberanyar. Kader di 2 Posyandu adalah kader yang telah diberikan pelatihan sebelumnya oleh Prodi D3 Kebidanan Universitas Ibrahimy. Pendampingan diberikan tentang cara pembuatan serbuk kelor hingga tahapan finishing produk camilan sehat KOMO. Hasil kegiatan pendampingan menunjukkan peningkatan keterampilan kader dalam pembuatan camilan sehat KOMO. Setelah dikonsumsi ibu hamil dampaknya juga langsung terlihat dengan adanya penurunan kejadian anemia (peningkatan kadar hemoglobin) $80 \%$ pada $10 \mathrm{ibu}$ hamil di wilayah Mimbo Sumberanyar dan 90\% ibu hamil di Wilayah Sumberejo.
\end{abstract}

Kata kunci: Anemia, coklat kelor, ibu hamil, kader, pendampingan

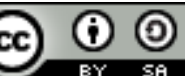

This is an open-acces article distributed under the terms of the Creative Commons Attribution-ShareAlike 4.0 International License.

\section{PENDAHULUAN}

Anemia Salah satu masalah gizi yang banyak terjadi pada ibu hamil adalah anemia gizi. World Health Organization (WHO) melaporkan bahwa terdapat 52\% ibu hamil mengalami anemia di negara berkembang. Hasil penelitian Chi, dkk (2007), menunjukkan bahwa angka kematian ibu adalah $70 \%$ untuk ibu-ibu yang anemia dan $19,7 \%$ untuk ibu yang non anemia. Ridwan (2007) menyatakan bahwa kematian ibu 15-20\% secara langsung atau tidak langsung berhubungan dengan anemia. Anemia pada kehamilan juga berhubungan dengan meningkatnya kesakitan ibu.

Program pencegahan anemia pada ibu hamil di Indonesia dengan memberikan suplemen tablet $\mathrm{Fe}$ sebanyak 90 tablet selama masa kehamilan. Laporan Puskesmas Banyuputih selama tiga tahun terakhir, ibu hamil di Kecamatan Banyuputih yang mengkonsumsi 90 tablet Fe cenderung mengalami penurunan drastis. 96,50\% pada tahun 2015, 105,41 pada tahun 2016 dan 75,87\% pada tahun 2017. 
Kebanyakan ibu hamil yang menolak atau tidak mematuhi anjuran ini karena berbagai alasan diantaranya yaitu banyak ibu hamil yang mengeluhkan tablet Fe bau amis sehingga menyebabkan ibu hamil yang mengkonsumsi mual hingga muntah. Ibu hamil yang mengalami mual sebagai dampak kehamilannya dapat merasakan mual yang lebih parah dibandingkan dengan ibu hamil yang tidak mengalami keluhan mual sebelumnya.

Beberapa cara yang dapat dilakukan untuk mengatasi mual akibat minum tablet besi. Salah satu cara yang dianjurkan untuk mengurangi mual sebagai efek samping dari mengkonsumsi tablet besi adalah dengan mengurangi dosis tablet besi dari 1 x 1 tablet sehari menjadi $2 \times 1 / 2$ tablet sehari. Selain itu bisa juga disiasati dengan konsumsi tablet Fe di malam hari sebelum tidur. Akan tetapi hal ini juga tidak sepenuhnya menyelesaikan masalah. Masih ditemui saja ibu hamil yang tidak berkenan untuk konsumsi tablet Fe.

Upaya terakhir yang umumnya dilakukan adalah dengan memaksimalkan konsumsi makanan yang kaya $\mathrm{Fe}$ dengan proses masak yang benar. Akan tetapi, masih banyak ibu yang tidak paham betul cara masak yang benar agar nutrisi tetap terjaga, belum lagi masalah porsi yang masih minimal. Oleh karena itu, dibutuhkan camilan siap saji yang terstandarisasi untuk dikonsumsi ibu hamil sebagai pengganti tablet Fe sementara ketika rasa mual akibat sensitivitas pada ibu hamil. Salah satunya camilan sehat tersebut adalah coklat (Kokoa) kelor (Moringa Oleifera) .

Kandungan kelor yang telah diolah menjadi serbuk memiliki kandungan nutrisi yang lebih tinggi dan konstan dibanding kelor segar. Kandungan Fe per 100g serbuk kelor yaitu 28,2 jauh lebih tinggi dibanding $100 \mathrm{~g}$ kelor segar yaitu 0,7 . Sedangkan coklat dapat dijadikan campuran dalam pembuatan coklat kelor, selain sebagai pemanis coklat juga memiliki kandungan $\mathrm{Fe}$, sehingga dapat memaksimalkan dalam upaya peningkatan kadar hemoglobin ibu hamil.

Menurut Notoatmodjo (2007), perilaku kesehatan dipengaruhi oleh faktor predisposing (predisposisi) diantaranya adalah pendidikan, pengetahuan, sikap, nilai dan kepercayaan. Faktor enabling (pemungkin) meliputi ketersediaan sarana dan prasana atau fasilitas kesehatan dan faktor reinforcing (penguat) meliputi dukungan keluarga, dukungan petugas kesehatan.

Sehingga dalam upaya penurunan kejadian anemia ibu hamil, perlu dilakukan pendampingan Kader Kokoa Moringa Oleifera (KOMO) dalam pembuatan camilan sehat coklat kelor.

\section{BAHAN DAN METODE}

Kegiatan pengabdian masyarakat pendampingan Kader Kokoa Moringa Oleifera ini dilakukan di 2 Posyandu di 2Desa, yaitu Posyandu Kenanga Desa Sumberejo dan Posyandu Asoka Mimbo Desa Sumberanyar. Kegiatan pendampingan dilakukan kepada kader kedua posyandu yang telah mendapatkan 2 kali pelatihan sebelumnya di Prodi D3 Kebidanan Fakultas Ilmu Kesehatan Universitas Ibrahimy.

Bahan yang dibutuhkan yaitu peralatan set membuat serbuk kelor yaitu wadah jaring untuk mencuci daun kelor, rak penjemur daun kelor, blender, ayakan 200mesh. Bahan baku KOMO, dark milk coklat, serbuk kelor, mente, almond, coklat mint. Peralatan memasak untuk proses pencampuran coklat kelor yaitu kompor, gas, wajan, panci, pisau, talenan, gloves, cetakan bar coklat, wadah. Bahan untuk bungkus camilan KOMO yaitu cutter, lem, alumunium foil untuk lapisan dalam dan kertas bahan art paper untuk bungkus luar. Bahan finishing yang dibutuhkan adalah stempel tanggal untu memberi tanda expired pada masing-masing produk. Dan toples, untuk kemasan dalam bentuk toples. Semua bahan telah diberikan sebagai hibah kepada masing-masing posyandu (kelompok mitra).

Kegiatan pendampingan dilakukan selama satu minggu di masing-masing rumah produksi Posyandu secara bergantian dilanjutkan dengan monitoring dan evaluasi setiap dua minggu satu kali. Pendampingan dilakukan dengan memastikan dan mengarahkan cara pembuatan coklat kelor dengan berbagai varians, hygienitas, proses pembekuan, penyimpanan, penyiapan bungkus dan finishing produk coklat kelor. Tahap terakhir yaitu didistribusikan kepada ibu hamil dan dilihat perbedaan kadar hemoglobin sebelum dan sesudah mengkonsumsi KOMO.

\section{Journal of Community Engagement in Health}


HASIL

Hasil pendampingan selama seminggu sebagaimana Tabel 1.

Tabel 1. Pendampingan Kader Kokoa Moringa Oleifera

\begin{tabular}{|c|c|c|c|}
\hline $\begin{array}{c}\text { Hari } \\
\text { Ke- }\end{array}$ & Kegiatan & Posyandu Kenanga & Posyandu Asoka \\
\hline 1 & $\begin{array}{l}\text { Penyiapan Bahan, } \\
\text { sangrai mente dan } \\
\text { almond. } \\
\text { Pemotongan bungkus } \\
\text { dalam KOMO. }\end{array}$ & $\begin{array}{l}\text { Kader dapat menyiapkan bahan } \\
\text { dan memotong bungkus KOMO } \\
\text { dengan baik. }\end{array}$ & $\begin{array}{l}\text { Kader dapat menyiapkan bahan } \\
\text { dan memotong bungkus KOMO } \\
\text { dengan baik }\end{array}$ \\
\hline 2 & $\begin{array}{l}\text { Pembuatan olahan } \\
\text { coklat kelor } 4 \text { Varians, } \\
3 \text { ukuran. } \\
\text { Packing KOMO. }\end{array}$ & $\begin{array}{l}\text { Kader dapat membuat KOMO, } \\
\text { akan tetapi masih kesulitan dalam } \\
\text { mengatur kecepatan pembuatan. } \\
\text { Kader masih kesulitan dalam } \\
\text { pembuatan KOMO varians Mint. }\end{array}$ & $\begin{array}{l}\text { Kader kesulitan dalam membuat } \\
\text { KOMO ukuran bar besar, hasil } \\
\text { selalu pecah. } \\
\text { Kecepatan pembuatan lebih tinggi } \\
\text { daripada proses pembungkusan. }\end{array}$ \\
\hline 3 & $\begin{array}{l}\text { Pembuatan olahan } \\
\text { coklat kelor } 4 \text { Varians, } \\
3 \text { ukuran. } \\
\text { Packing KOMO. }\end{array}$ & $\begin{array}{l}\text { Kader dapat melakukan } \\
\text { pembuatan dan pembenkuan } \\
\text { KOMO secara efektif. } \\
\text { Kader masih kelusitan dalam } \\
\text { membuat KOMO varians mint. }\end{array}$ & $\begin{array}{l}\text { Kader sudah bisa membuat bar } \\
\text { besar dengan baik. } \\
\text { Kader membuat KOMO dengan } \\
\text { cara } 1 \text { orang fokus membuat, dan } \\
\text { lainnya menyiapkan bungkus dan } \\
\text { membungkus. Sehingga menjadi } \\
\text { efektif. }\end{array}$ \\
\hline 4 & $\begin{array}{l}\text { Pembuatan olahan } \\
\text { KOMO ukuran Bar } \\
\text { Besar\&mint. }\end{array}$ & $\begin{array}{l}\text { Kader dapat membuat KOMO bar } \\
\text { besar dan Mint dengan baik. }\end{array}$ & $\begin{array}{l}\text { Kader dapat membuat KOMO bar } \\
\text { besar dan Mint dengan baik. }\end{array}$ \\
\hline 5 & $\begin{array}{l}\text { Packing bungkus dalam } \\
\text { KOMO. }\end{array}$ & $\begin{array}{l}\text { Kader dapat membungkus } \\
\text { KOMO menggunakan alumunium } \\
\text { foil dengan benar. }\end{array}$ & $\begin{array}{l}\text { Kader dapat membungkus KOMO } \\
\text { menggunakan alumunium foil } \\
\text { dengan benar. }\end{array}$ \\
\hline 6 & $\begin{array}{l}\text { Packing bungkus luar } \\
\text { KOMO dan Finishing }\end{array}$ & $\begin{array}{l}\text { Kader masih belum dapat } \\
\text { membungkus bagian luar. }\end{array}$ & $\begin{array}{l}\text { Kader masih sering } \\
\text { memberikan label exp date }\end{array}$ \\
\hline 7 & $\begin{array}{l}\text { Packing bungkus luar } \\
\text { KOMO dan Finishing }\end{array}$ & $\begin{array}{l}\text { Kader dapat melakukan finishing } \\
\text { KOMO dengan baik. }\end{array}$ & $\begin{array}{l}\text { Kader dapat melakukan finishing } \\
\text { KOMO dengan baik. }\end{array}$ \\
\hline
\end{tabular}

Berdasarkan Tabel 1 menunjukkan bahwa setelah dilakukan pendampingan selama satu minggu, kader telah mandiri dan dapat membuat produk camilan sehat KOMO dengan baik.

Untuk pembuatan serbuk kelor dilakukan setelah stok serbuk kelor hibah menipis. Pembuatan serbuk kelor tidak menjadi prioritas untuk awal, karena proses adaptasi kader yang kesulitan membagi waktu antara membuat pesanan KOMO dengan proses pembuatan serbuk kelor. Pembuatan serbuk kelor baru terealisasi 1 bulan pasca pendampingan dan hanya dilakukan oleh kelompok mitra Pembuatan serbuk kelor memakan waktu 2 minggu untuk pengeringan dan penggerusan serta pengayaan di hari ke 15 dan 16. 
Setelah kader mahir dalam membuat camilan sehat KOMO kemudian didistribusikan kepada ibu hamil dan dipantau kadar hemoglobin sebelum mengkonsumsi KOMO dan 1x24 jam sesudah konsumsi. Pendistribusian dan pemantauan dilakukan saat kelas ibu hamil Desa Sumberejo. Sedangkan Untuk Mimbo Desa Sumberanyar dilakukan kepada ibu hamil terdekat. Hasil pemantauan kadar Hb sesudah ibu hamil konsumsi camilan sehat KOMO sebagaimana Gambar 1.

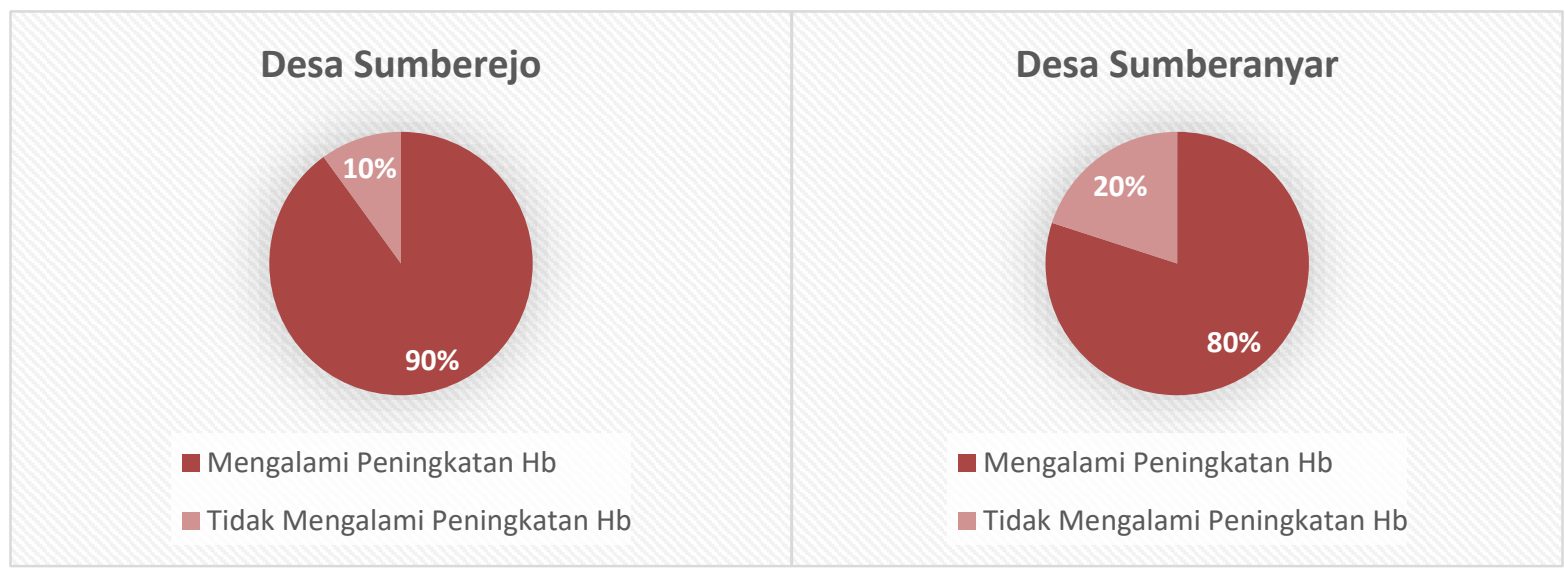

Gambar 1. Pemantauan Kadar Hb Ibu Hamil Sesudah Konsumsi KOMO di Desa Sumberejo dan Sumberanyar (Mimbo)

Berdasarkan Gambar 1 menunjukkan bahwa terjadi peningkatan kadar hemoglobin ibu hamil sesudah konsumsi KOMO, baik di Desa Sumberejo dan Desa Sumberanyar.

\section{PEMBAHASAN}

Berdasarkan hasil kegiatan pendampingan secara keseluruhan kelompok mitra telah mampu mandiri membuat camilan sehat KOMO sebagai pengganti sementara ataupun camilan ringan yang sehat bagi ibu hamil dalam menanggulangi anemia. Hal ini sesuai sebagaimana pengertian dari pendampingan yaitu pekerjaan yang dilakukan oleh fasilitator atau pendamping masyarakat dalam berbagai kegiatan program. Suharto (2005) menguraikan bahwa pendampingan merupakan satu strategi yang sangat menentukan keberhasilan program pemberdayaan masyarakat.

Pendampingan sebagai suatu strategi yang umum digunakan oleh pihak luar dalam upaya meningkatkan mutu dan kualitas dari sumber daya manusia, sehingga mampu mengindentifikasikan dirinya sebagai bagian dari permasalahan yang dialami dan berupaya untuk mencari alternative pemecahan masalah yang dihadapi.

Dalam hal ini masalah kader dalam menanggulangi anemia bagi ibu hamil melalui camilan sehat KOMO sebagai pengganti sementara tablet Fe dapat direalisasikan. Hasil pemantauan juga berdampak langsung. Hal ini terbukti dari hasil pemantauan kepada $10 \mathrm{ibu}$ hamil di masing-masing wilayah mitra didapatkan bahwa 80\%-90\% ibu hamil mengalami peningkatan kadar $\mathrm{Hb}$, dari yang sebelumnya berstatus anemia menjadi normal. Tentu diimbangi dengan istirahat yang cukup. Ibu hamil yang mengalami anemia memiliki daya serap Fe yang lebih tinggi dibanding ibu hamil yang normal. Oleh karena itu dengan adanya asupan tambahan berupa camilan sehat KOMO yang kaya Fe, dengan konsumsi 1x bisa langsung terlihat hasilnya. Sehingga, apabila kader terus melakukan edukasi dan menyediakan stok camilan sehat KOMO ini, kejadian ibu hami anemia akan terus menurun.

\section{KESIMPULAN}

Kesimpulan kegiatan pendampingan kader KOMO ini menunjukkan bahwa kader dapat membuat produk camilan sehat bergizi bagi ibu hamil anemia dengan baik secara mandiri. Dampaknya juga langsung dirasakan yaitu dengan adanya penurunan angka anemia ibu hamil di wilayah mitra. Saran dalam kegiatan pendampingan ini adalah 1) Perlu adanya pembagian waktu dan

\section{Journal of Community Engagement in Health}


tugas yang baik dalam pembuatan serbuk kelor dan produk KOMO. 2) Selain itu, dibutuhkan juga kesabaran dan pencarian teknik pembungkusan KOMO yang efektif. 3)Dibutuhkan konsistensi kekompakan dan motivasi kader agar kegiatan terus berlanjut.

\section{UCAPAN TERIMAKASIH}

Ucapan terimakasih penulis sampaikan untuk pihak-pihak yang telah membantu dalam mensukseskan kegiatan, khususnya untuk DRPM Kemenristekdikti RI yang telah mendanai kegiatan pengabdian masyarakat Program Kemitraan Masyarakat (PKM) ini.

\section{REFERENSI}

Almatsler, S. (2009). Prinsip Dasar Ilmu Gizi. Jakarta: PT. Gramedia Pustaka

Bey. (2010). All Things Moringa.

Dinas Kesehatan Kabupaten Situbondo. (2015). Profil Kesehatan Kabupaten Situbondo. Situbondo:

Dinas Kesehatan Kabupaten Situbondo

Fatimah, H. et al. (2011). Pola Konsumsi dan Kadar Hemoglobin Pada Ibu Hamil di Kabupaten

Maros Sulawesi Selatan. Makara Kesehatan, 15(1), pp: 31-36.

Fuglie, L. J. (2001). The Miracle Tree: Moringa oleivera: Natural Nutrition for the Tropics. Training Manual. Church World Service. Dakar, Senegal

Gopalan, C. (2010). Nutrition Research in Southeast Asia. New Delhi, WHO

Harvey, L.J., et al. (2007). Effect of high-dose iron supplements on fractional zinc absorption and status in pregnant women. American Journal of Clinical Nutrition, 85 (1), pp : 131-136.

Hinderaker SG, Olsen BE, Lie RT, et al. (2002). Anemia in pregnancy in rural Tanzania: associations with micronutrients status and infections. Eur. J. Clin. Nutr, 56(3), pp :192-1 